\title{
Design of the Synchronous Generator Excitation Control System Based on DSP
}

\author{
Dandan $\mathrm{Ma}^{1, \mathrm{a}}$,Ping $\mathrm{Xin}^{1, \mathrm{~b}^{*}}$ and Hongtao $\mathrm{Mi}^{1, \mathrm{c}}$ \\ ${ }^{1}$ Beihua University College of Electrical and Information Engineering \\ aMadandan11@126.com, b359411897@qq.com, ${ }^{\mathrm{c}} 17207527 @ q q . c o m$
}

Keywords: Excitation Controller; TMS320F2812; Synchronous Generator; PID

\begin{abstract}
The excitation controller is an important part of the synchronous generator excitation system, which is important for the safe and stable operation of the power system and generator.In this paper, a DSP excitation controller based on TMS320F2812 is proposed based on the current research situation of excitation adjustment devices at home and abroad.In this paper, the hardware circuits are designed. Finally, completed a small simulation control system experiment, the results show that the excitation controller based on DSP has simple hardware structure, high reliability, maintenance is convenient.
\end{abstract}

\section{Introduction}

The excitation control system of synchronous generator consists of two parts: excitation power unit and excitation regulator.The excitation power unit is used to provide excitation energy for the synchronous generator.The main function of the excitation regulator is to control the excitation power unit in real time.

In recent years, the new large-capacity generating units in China have basically adopted DER(digital based excitation regulator),It has the advantages which simulating exciter can not achieve and its technology is becoming more and more mature.In this paper, the excitation current of generator excitation winding is regulated by PWM signal.Thus, the generator outputs a constant voltage and maintains the system balance.After the generator network, its main function is to control the power distribution between the units to ensure the stability and safety of the power grid operation.

\section{Design of Synchronous Generator Excitation Controller}

Design Requirements. The excitation controller can accurately detect the voltage change of generator terminals, and generate the corresponding digital instruction according to its fluctuation, Using DSP to generate electrical signals to control MOSFET shutdown, to adjust the magnitude of the excitation current, so the output voltage is maintained in a certain range.

(2) The designed excitation controller is maneuverable and small in volume.

(3) The theoretical foundation is strong, the actual hardware is reliable.

(4) The program is readable and the modules are programmed.

(5) The test results meet the requirements and the data is reasonable.

Controller Overall Design. The main control hardware of the excitation controller is MOSFET . Acquiried output voltage, then it is fed into the field winding. The excitation current is adjusted by controlling the switching time of the excitation winding circuit, then control the output voltage.The overall design is shown in Fig.1: 


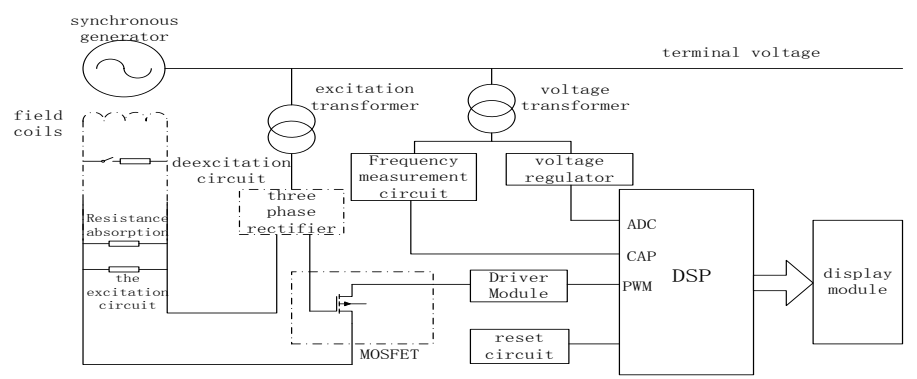

Figure 1. General design of excitation controller

The detection circuit enters the three-phase alternating current after the filter into TMS320F2812 $\mathrm{AD}$, The results of the conversion will be calculated by DSP, Then the corresponding control signal is output to control the cutting of MOSFET, This will control the current in the excitation circuit to change the output voltage of the generator. When the system detects that the generator terminal voltage is too large, the internal command of DSP can directly cut MOSFET off to achieve the purpose of failure protection.

\section{Hardware Circuit Design}

Hardware Composition. Fig.2 is a block diagram of hardware components. The excitation controller in this design has the following modules:

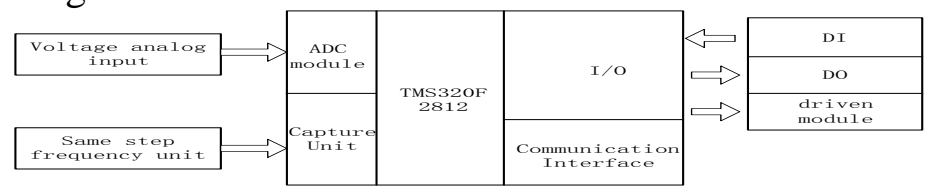

Figure 2. Basic hardware block diagram

The capture unit exists in the event manager of TMS320F2812 chip, We will use this capture unit to collect the voltage and frequency of the generator. The change of the machine voltage enter into the DSP, then generate control quantity by software calculation. Changing the control quantity can change the output size of excitation current and realize a series of failure protection functions.

Reset Circuit. When the excitation controller crashed due to an irresistible factor or in the case of carton, we can make it continue normal by the switch of the reset circuit. The reset circuit is shown in Fig.3:

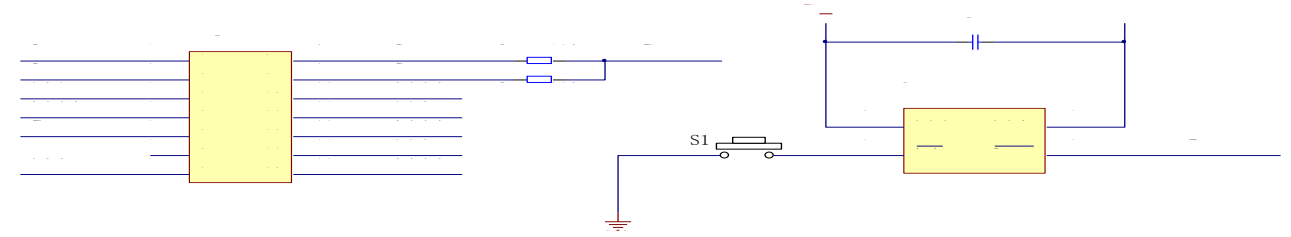

Figure 3. reset circuit

Voltage Sampling Circuit. The terminal voltage of the sampling generator is obtained from the voltage transformer. The output voltage range is $0 \sim 100 \mathrm{~V}$. The AD input voltage in TMS320F2812 under $3 \mathrm{~V}$.Therefore, we will design a voltage signal adjusting circuit to meet the voltage requirements of the $\mathrm{AD}$ sampling module.Its design circuit is shown in Fig.4:

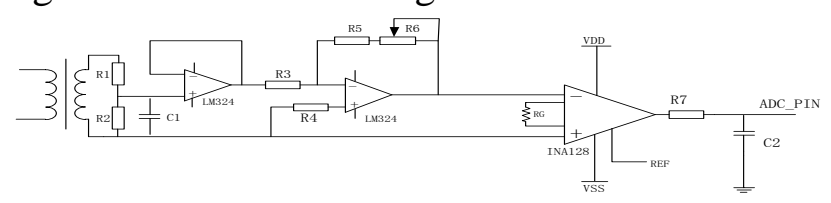

Figure 4. Voltage regulating circuit

Frequency Measurement Circuit. The frequency measurement circuit can sample requency in real time, Select a phase voltage as the frequency measurement signal, its circuit is shown in Fig.5: 


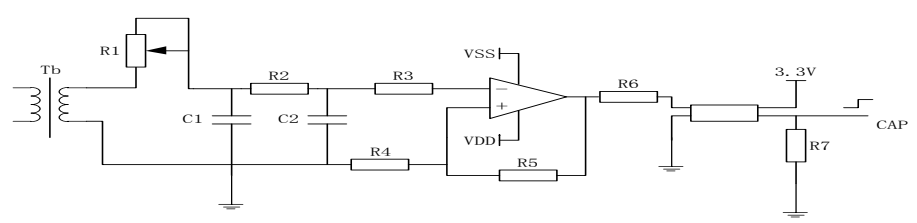

Figure5. Frequency measurement circuit

Liquid Crystal Display Circuit. The LCD1602 liquid crystal display module is selected in the design, and its circuit wiring is shown in Fig.6:

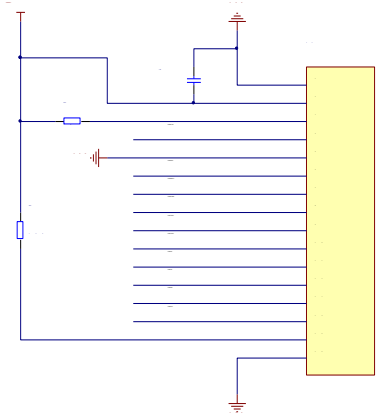

Figure 6. 1602Liquid crystal wiring diagram

\section{Software Design}

Software is divided into two main modules: main program and interrupt program. In each module there are also some necessary subroutines, such as delayed programs, initialization programs, etc. The main program includes initialization, analog calculation, control adjustment and liquid crystal display.In the interrupt program, it mainly includes the interruption of $\mathrm{A} / \mathrm{D}$ transformation and the interruption of fault protection. The flow chart of its main program is shown in Fig.7:

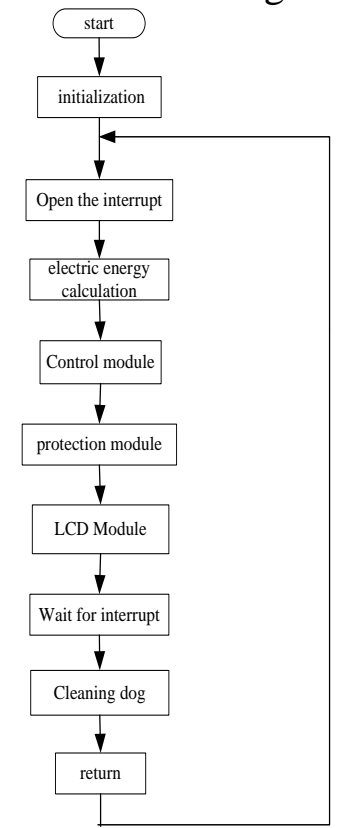

Figure 7. Master program flow diagram

\section{Test Methods and Results}

In the physical experiment, a simple simulation device is used to illustrate the implementation principle and implementation of the excitation control device. The specific circuit diagram is shown in Fig.8: 


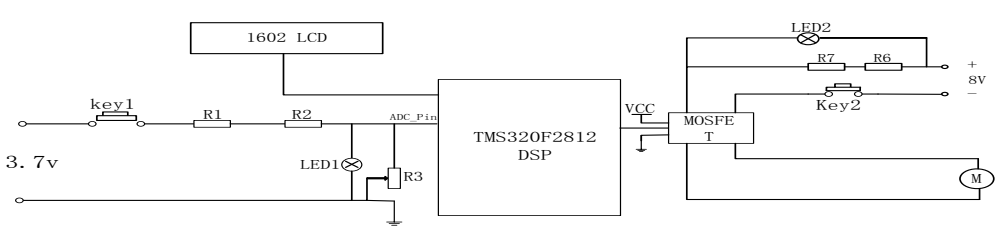

Figure 8. Analog controller circuit diagram

Hardware Select. Select the number of components and components of the components, the results are shown in Table 1:

Table1 Component details

\begin{tabular}{|c|c|c|c|c|}
\hline indicia & name & indicator & model & remarks \\
\hline R1 & resistor & $220 \Omega$ & Conventional & \\
\hline R2 & resistor & $47 \Omega$ & Conventional & \\
\hline R3 & resistor & $0-1000 \Omega$ & Conventional & \\
\hline R4 & resistor & $470 \Omega$ & Conventional & \\
\hline R5 & resistor & $47 \Omega$ & Conventional & \\
\hline R6 & resistor & $97 \Omega$ & Conventional & \\
\hline R7 & resistor & $107 \Omega$ & Conventional & \\
\hline MOSFET & $\begin{array}{c}\text { Switch } \\
\text { element }\end{array}$ & & Grove-mosfet module & \\
\hline
\end{tabular}

Experimental Results and Analysis. The main effect of the excitation controller is to adjust the excitation current to make the generator terminal voltage output stable. We set up a small $0 \sim 3.7 \mathrm{v} \mathrm{dc}$ circuit to simulatie system. In the circuit In this test, the standard voltage is $1.8 \mathrm{v}$

slide rheostat range of $0 \sim 1000 \Omega$ to simulate the output voltage fluctuates. And the dc power supply is outputed to the dc fan to simulate the speed adjustment of the turbine.

In this test, the standard voltage is $1.8 \mathrm{v}$, When the voltage is less than $60 \%$ of the marked voltage $(1.08 \mathrm{~V})$, strong excitation is carried out; Turn off excitation when the voltage is over $150 \%$ of the standard voltage $(2.70 \mathrm{~V})$. The results of the experiment are as follows:
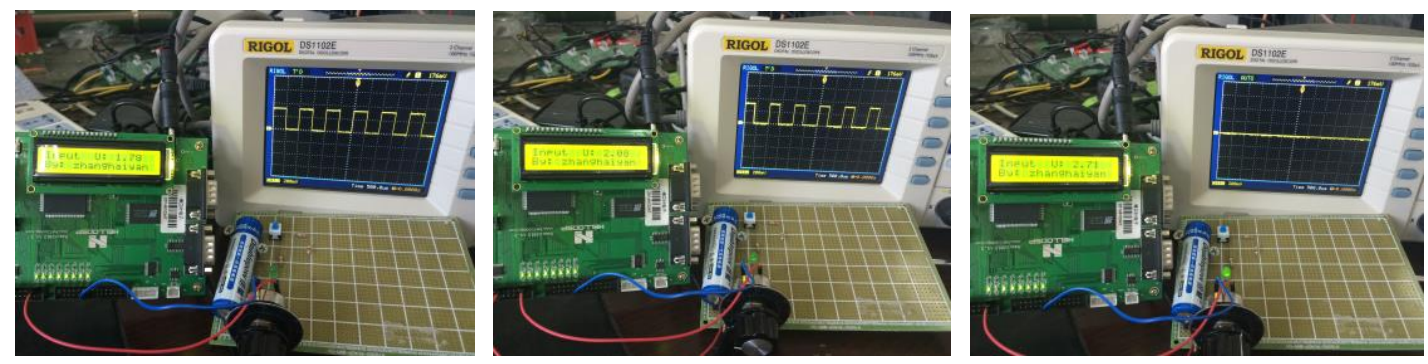

Figure 9. The results of the experiment when the voltage moves up
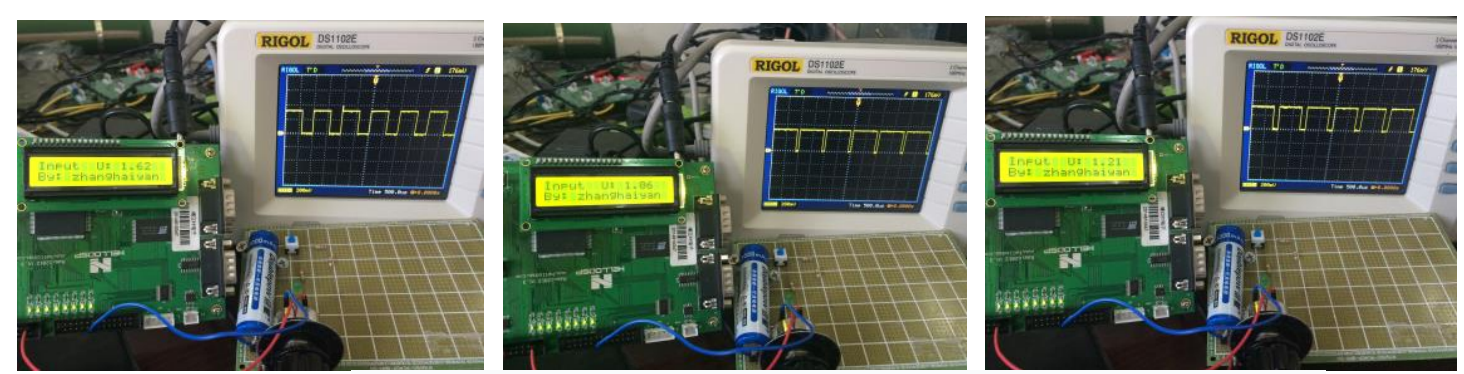

Figure 10. The results of the experiment when the voltage goes down 
By adjusting the voltage size, it can control the speed of the small fan, that is, it can control the output current, and its value is inversely with the sampling voltage. The results show that the simulation system can achieve the desired effect and proves the feasibility of this design.

\section{Acknowledgements}

This research was financially supported by the Education Department Project of Jilin Province [SGJY201606] and [2016] 56nd; Education and teaching research topics of Beihua University [XJQN2017030]; Innovation and entrepreneurship projects of College Students [201510201011].

\section{Reference}

[1] HU Bin, WANG Yan, YU Junpeng.Variable Excitation Control Strategy for Electrically Excited Synchronous Generator[J].Journal of Power Supply,2017,15(3):176-180.

[2] PENG Fei, WANG Xiaoyan.Research on PID excitation controller based on improved BP neural network[J].Sulphuric Acid Industry,2017,(5):46-52.

[3] ZHOU Shuang, WANG Jie.Coordinated stabilization control of generator excitation with STATCOM in power system with nonlinear loads[J].JOURNAL OF EIECTRIC POWER SCIENCE AND TECHNOLOGY,2017,32(2):17-22.

[4] PAN Xiang,JIN Jiajie,LU Zibao.On self-triggered excitation control of synchronous generators[J].JOURNAL OF UNIVE RSITY OF JINAN,2016,30(5):364-367.

[5] Chen Fazhi.Research and Development of Synchronous Generator Excitation Control System [D].Huazhong University of Science and Technology, 2009.

[6] ZHANG Hong,HAO Yi-na,LIU Xu, Jiang Feng.Research on Control Performance Evaluation of Synchronous Generator Excitation System[J].Computer Simulation,2016,33(11):390-394.

[7] M Messadi, A Mellit, K Kemih. Predictive control of a chaotic permanent magnet synchronous generator in a wind turbine system [J]. Chinese Physics B，2015，24(1): 177-183.

[8] Liu Keliang. Design of Automatic Excitation Control Device for Synchronous Generator[D]. Xi'an University of Science and Technology, 2013.

[9] Juan Yu. A Summary on Algorithm Research of Synchronous Generator Excitation Control[J]. Trans Tech Publications, 2012, 21(8): 309-313.

[10] Nalin Mohanty . Implenentation of DSP Based Cost Effective Inverter Fed Induction Motor Drive with VisSim[J]. De Grugter, 2012，3(6): 115-119.

[11] D Sumina, I Erceg, G Erceg. DSP based simulator for excitation control of synchronous generator[J]. World Scientific and Engineering Academy and Society, 2009, 4 (11) : 531-540. 